Supplementary Information for:

\title{
Colorimetric detection of sepsis-derived hyperdegranulation with
}

\section{plasmonic nanosensors}

Giulia Santopolo, ${ }^{1,2, \ddagger}$ Antonio Clemente, ${ }^{1, \neq, *}$ Maria Aranda, ${ }^{3}$ Antonia Socias, ${ }^{3}$ Alberto del Castillo, ${ }^{3}$ Aniceta Chica, ${ }^{4}$ Marcio Borges ${ }^{3}$ and Roberto de la Rica. ${ }^{1, *}$

Corresponding authors: antonio.clemente@ssib.es; roberto.delarica@ssib.es

${ }^{1}$ Multidisciplinary Sepsis Group, Health Research Institute of the Balearic Islands (IdISBa), 07120, Palma, Spain.

${ }^{2}$ Chemistry Department, University of the Balearic Islands (UIB), 07122, Palma, Spain.

${ }^{3}$ Multidisciplinary Sepsis Unit, ICU, Son Llàtzer University Hospital, 07198, Palma, Spain. ${ }^{4}$ Immunology Department, Son Espases University Hospital, 07120, Palma, Spain.

\section{Contents}

Table S1. Demographic characteristics and clinical data of septic patients.

Figure S1. Optimization of degranulation protocol.

Figure S2. Phenotyping of neutrophilic granulocytes and ascertainment of degranulation.

Figure S3. Detection of granule-derived MPO in cultures of control and septic granulocytes.

Figure S4. Spectra of AuNPs in the presence of MPO.

Figure S5. Detection of MPO at different $\mathrm{pH}$ values with plasmonic nanosensors

Table S2. Limit of detection and linear range for MPO at different $\mathrm{pH}$ values.

Figure S6. Aggregation pattern of AuNPs in the presence of GOx.

Figure S7. Detection of MPO at different $\mathrm{pH}$ values in the presence of GOx.

Figure S8. Spectra of AuNPs in the presence of MPO with GOx interference.

Figure S9. Isoelectric focusing of cell lysates after ionomycin stimulation. 
Figure S10. pH-dependent interaction of granule-derived MPO with AuNPs.

Figure S11. Spectra of AuNPs in the presence of RPMI.

Figure S12. Spectra of AuNPs in the presence of DMSO and ionomycin.

Figure S13. $\mathrm{A}_{670}$ of SNs in the absence of AuNPs.

Figure S14. Aggregation of AuNPs with SNs from non-stimulated cultures.

Figure S15. Plasmonic assay with granule-depleted cells.

Figure S16. Color quantification from photographs.

Figure S17. Correlation between plasmonic nanosensor signals and platelet counts. 
Table S1. Demographic characteristics and clinical data of septic patients.

\begin{tabular}{|c|c|c|c|c|c|c|c|c|c|c|c|c|}
\hline $\mathbf{P x}$ & Age & Sex & $\begin{array}{l}\text { Septic } \\
\text { shock }\end{array}$ & $\begin{array}{c}\text { SOFA } \\
\text { score }\end{array}$ & Focus & $\mathrm{HC}$ & $\begin{array}{c}\text { CRP } \\
\mathrm{mg} \mathrm{dL}^{-1}\end{array}$ & $\begin{array}{c}\text { PCT } \\
\mathrm{ng} \mathrm{mL}^{-1}\end{array}$ & $\begin{array}{l}\text { Lactate } \\
\text { mmol L }^{-1}\end{array}$ & $\begin{array}{c}\text { Platelets } \\
10^{3} \mu \mathrm{L}^{-1}\end{array}$ & $\begin{array}{c}\text { Creatinine } \\
\mathrm{mg} \mathrm{dL}^{-1}\end{array}$ & $\begin{array}{c}\text { Outcome } \\
\text { at ICU }\end{array}$ \\
\hline 1 & 81 & $\mathrm{M}$ & YES & 9 & $\mathrm{ABD}$ & + & 250,8 & 19,21 & 2,5 & 112 & 2,7 & Discharged \\
\hline 2 & 61 & $\mathrm{~F}$ & NO & 4 & $\mathrm{ABD}$ & - & 422 & 330,3 & 4,5 & 206 & 2,25 & Discharged \\
\hline 3 & 79 & $\mathrm{~F}$ & YES & 9 & ABD & - & 263 & 13,25 & 1,9 & 348 & 1,36 & Discharged \\
\hline 4 & 67 & M & YES & 8 & ABD & + & 427,9 & 23,67 & 1 & 960 & 2,2 & Exitus \\
\hline 5 & 49 & M & NO & 4 & $\mathrm{ABD}$ & - & 269 & 0,54 & 0,9 & 259 & 0,5 & Discharged \\
\hline 6 & 32 & $\mathrm{~F}$ & $\mathrm{NO}$ & 2 & UT & - & 238 & 18,35 & 1,1 & 140 & 1,51 & Discharged \\
\hline 7 & 83 & $\mathrm{~F}$ & YES & 8 & NA & - & 10,2 & 35,92 & 4 & 220 & 2,85 & Discharged \\
\hline 8 & 65 & M & YES & 8 & Lung & NA & 383 & 1,41 & 1,1 & 686 & 0,7 & Discharged \\
\hline 9 & 71 & M & YES & 7 & $\mathrm{ABD}$ & + & 373 & 22 & 1,4 & 108 & 1,4 & Discharged \\
\hline
\end{tabular}

Normal range: $\quad 0-5 \quad 0-0,05 \quad 0,5-2,2 \quad 150-400 \quad 0,72-1,25$

M: male, F: female, SOFA: sepsis-related organ failure assessment, ABD: abdominal, UT: urinary tract, HC: hemoculture, NA: not available, CRP: C-reactive protein, PCT: procalcitonin, ICU: intensive care unit. 


\section{S1. Optimization of degranulation protocol}

Total granulocytes were isolated from peripheral blood of 3 healthy donors and $500 \mu \mathrm{L}$ of cell suspensions at $10^{3}$ cells $\cdot \mathrm{mL}^{-1}$ in RPMI medium were added to $1.5 \mathrm{~mL}$ Eppendorf conical tubes pre-blocked with $2 \%$ PBS-BSA. Next cells were stimulated with $1,2.5$ or $5 \mu \mathrm{M}$ ionomycin during $5,10,20$ or $30 \mathrm{~min}$ at $37^{\circ} \mathrm{C}$. Cell-free supernatants (SNs) were obtained by centrifuging cultures for $5 \mathrm{~min}$ at $1700 \mathrm{rpm}$. Then we evaluated the CD63 expression (degranulation marker) and the fluorescence of DAPI (cell viability marker) in cell pellets by using flow cytometry and the peroxidase activity in cell-free SNs by adding TMB substrate (as explained in the Materials and Methods section of the main text). We evaluated the increase $(\Delta)$ in all parameters by subtracting the values yielded with $0.7 \mathrm{mM}$ DMSO (ionomycin solubilizer) for each experimental condition.

In Fig. S2A the highest increase of membrane CD63 expression was found by using $2.5 \mu \mathrm{M}$ ionomycin between 10 and $20 \mathrm{~min}$. This agreed with higher peroxidase activity in SNs in the same experimental conditions (Fig. S2B). Fig. S2C shows that the higher ionomycin concentration and incubation time the higher cell death (\% of DAPI+ cells). We chose 2.5 $\mu \mathrm{M}$ ionomycin for $15 \mathrm{~min}$ as the optimal conditions to induce degranulation without substantially compromising cell viability.
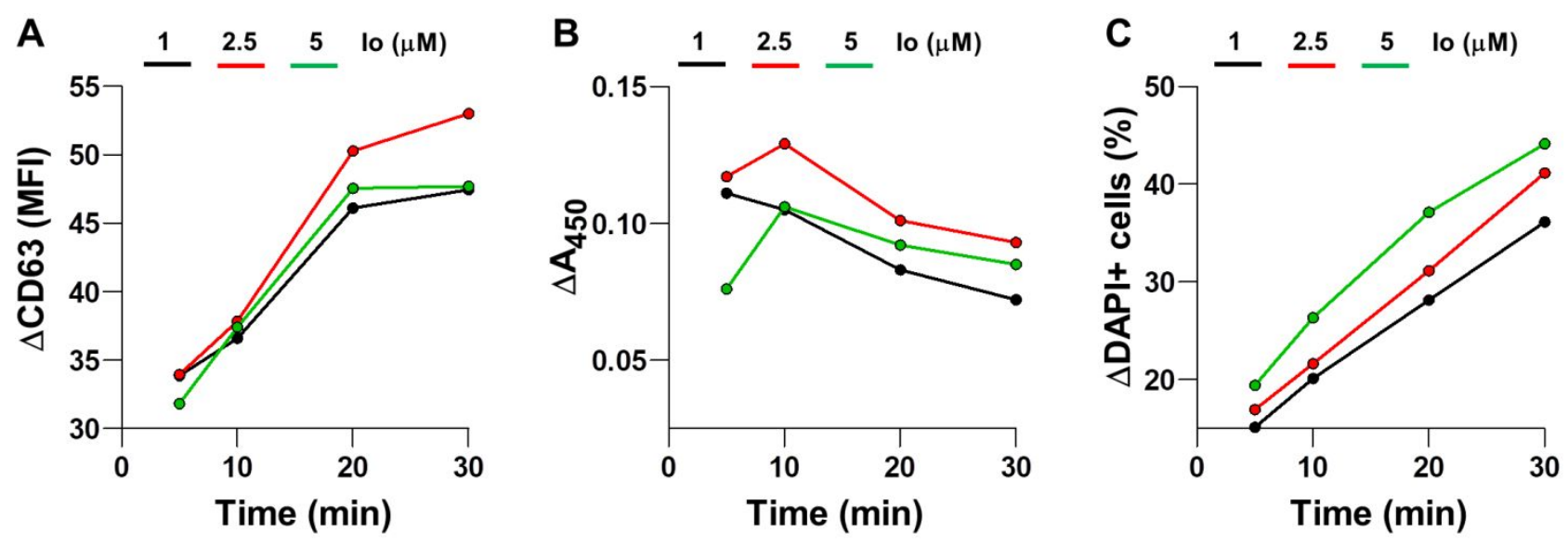

Figure S1. Optimization of the degranulation protocol. Median fluorescence intensity (MFI) of CD63 (A), peroxidase activity in SNs (B) and DAPI+ cells percentage (C) with respect to incubation time with ionomycin at $1 \mu \mathrm{M}$ (black), $2.5 \mu \mathrm{M}$ (red) or $5 \mu \mathrm{M}$ (green). Data are expressed as the increase $(\Delta)$ with respect to DMSO controls for each experimental condition. Dots represent de average of 3 independent experiments. 


\section{S2. Phenotype of neutrophilic granulocytes and validation of the degranulation protocol}

After performing the surface membrane staining protocol detailed in Materials and Methods section we analyzed the phenotype of neutrophilic granulocytes with the following flow cytometric gating strategy. First total granulocytes were selected in a dot-plot diagram displaying side scatter (SSC) and forward scatter (FSC) parameters. Then DAPI-negative viable cells were selected and displayed in a dot-plot diagram showing SSC and CD11bFITC fluorescence. Thus $\mathrm{CD}_{11} \mathrm{~b}^{+}$cells were selected and displayed in a dot-plot diagram showing CD16-PCy5 and CD13-PE fluorescence. Finally CD $16^{+} \mathrm{CD} 13^{+}$cells (neutrophilic granulocytes) were gated and the median fluorescence intensity (MFI) of CD63-PCy7 was quantified in a histogram in order to evaluate their degranulation status.

We also validated our degranulation protocol by detecting peroxidase activity in the SNs. Briefly, $50 \mu \mathrm{L}$ of ready-to-use 1-Step Ultra TMB (Thermo Scientific) was added to $50 \mu \mathrm{L}$ of cell-free SNs (previously diluted 1:2 in RPMI-1640 medium) in BSA-blocked wells of a 96well plate. After $10 \mathrm{~min}$ of incubation at RT the colorimetric reaction was stopped with 100 $\mu \mathrm{L}$ of $4 \mathrm{~N} \mathrm{H}_{2} \mathrm{SO}_{4}$, and absorbance was measured at $450 \mathrm{~nm}$. Absorbance measures were performed in a PowerWave HT plate reader (Biotek).

As expected, in Fig. S2A the phenotype of neutrophilic granulocytes from healthy donors is $\mathrm{CD} 11 b^{\text {high }} \mathrm{CD} 13^{\text {high }} \mathrm{CD} 16^{\text {high }}$. Stimulation with ionomycin decreases granularity of cells (lower SSC) and increases the surface expression of the degranulation marker CD63 (histograms in Fig. S2A and Fig. S2B). Finally, in Fig. S2C peroxidase activity in SNs is remarkably higher when cells are stimulated with ionomycin in comparison to DMSO. These results validate the proposed degranulation protocol to obtain samples enriched with granulederived proteins. 

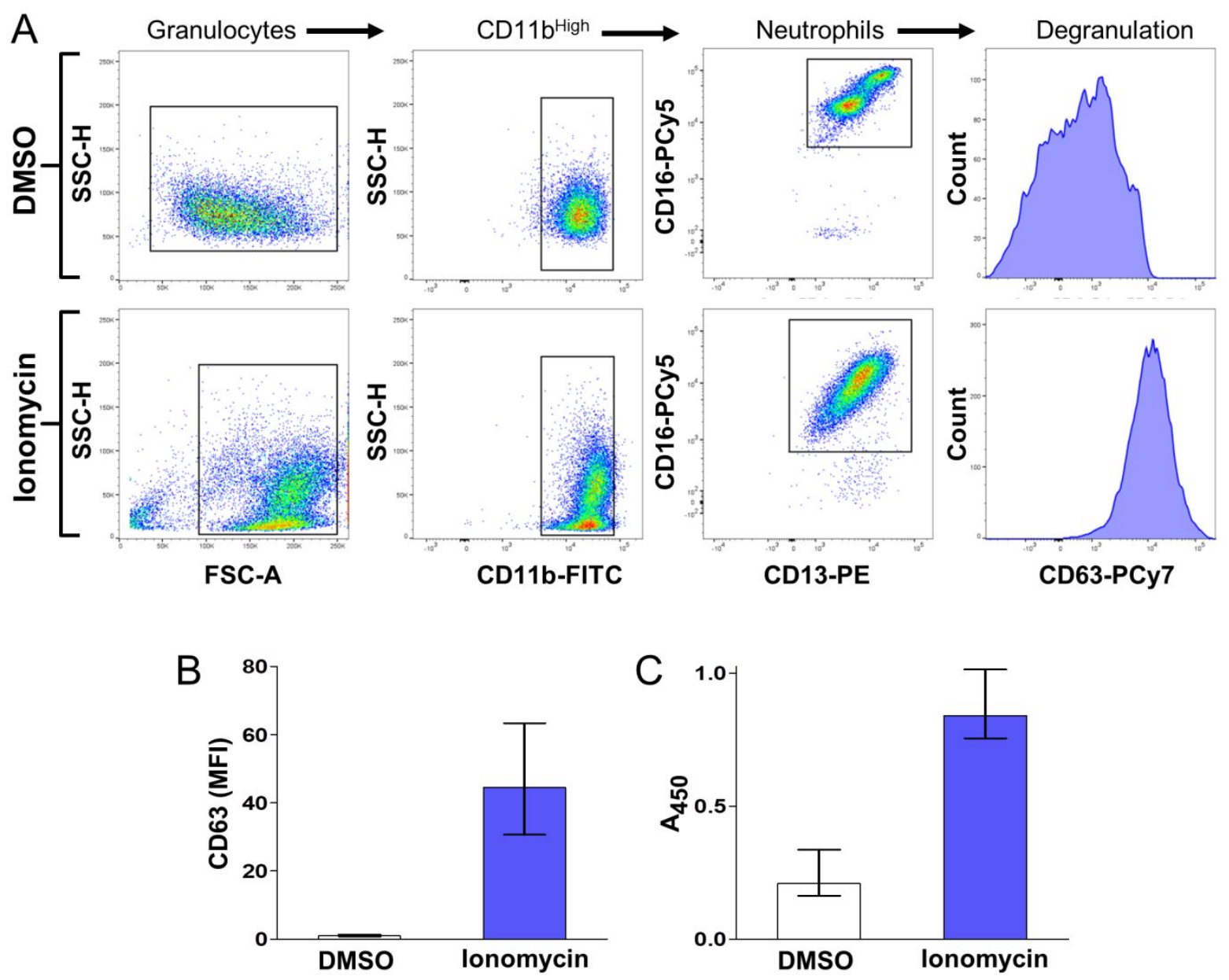

Figure S2. Phenotyping of neutrophilic granulocytes and ascertainment of degranulation. Evaluation of induced degranulation marker CD63 (histograms) in neutrophilic granulocytes identified as $\mathrm{CD} 11 \mathrm{~b}^{\mathrm{High}} \mathrm{CD} 16^{\mathrm{High}} \mathrm{CD} 13^{\mathrm{High}}$ (dot-plot diagrams) after stimulation with ionomycin (lower row in A) or DMSO (upper row in A). Median fluorescence intensity (MFI) of degranulation marker CD63 in neutrophilic granulocytes (B) after stimulation with ionomycin (blue) or DMSO (white). Absorbance at $450 \mathrm{~nm}$ as peroxidase activity measure in SNs of granulocytes cultures (C) after stimulation with ionomycin (blue) or DMSO (white). Error bars are the standard deviation of 15 healthy controls. 


\section{S3. MPO ELISA}

We analyzed the levels of MPO released to SNs of granulocytes cultures from healthy donors and septic patients. After following our degranulation protocol (explained in the Materials and Methods), $100 \mu \mathrm{L}$ of cell-free SNs (obtained from 2 independent cultures for each participant in the study) was kept at $-20{ }^{\circ} \mathrm{C}$ until use. For the evaluation of MPO we performed a sandwich ELISA (Abyntek) by following manufacturers' instructions.

In Fig. S3 MPO levels detected in SNs of ionomycin-stimulated granulocytes from healthy controls are higher than those from septic patients. These results together with the higher basal expression of degranulation marker CD63 in septic neutrophilic granulocytes (Fig. 5A in the main text) demonstrate that lower levels of cationic proteins are released in vitro because they have degranulated in vivo.

Comparing the average concentration of MPO in healthy volunteers $\left(1.0 \pm 0.6 \mu \mathrm{g} \mathrm{mL}^{-1}\right)$ with the total protein in the sample measured with a Bradford assay $\left(5 \pm 2 \mu \mathrm{g} \mathrm{mL}^{-1}\right)$ revealed that at least $20 \%$ of the supernatant composition consisted of cationic proteins.

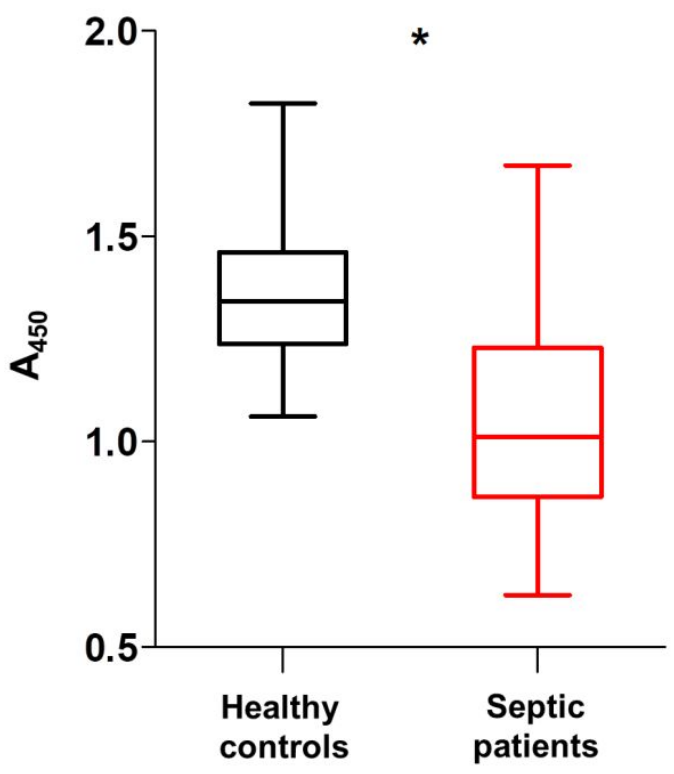

Figure S3. Detection of granule-derived MPO in cultures of control and septic granulocytes. Signals of MPO yielded by ELISA (absorbance at $450 \mathrm{~nm}$ ) in SNs of ionomycin-stimulated granulocytes from healthy controls (black box, $n=28$ ) and septic patients (red box, $n=18$ ). ${ }^{*} \mathrm{p}<0.05$ was obtained with a Mann-Whitey test 

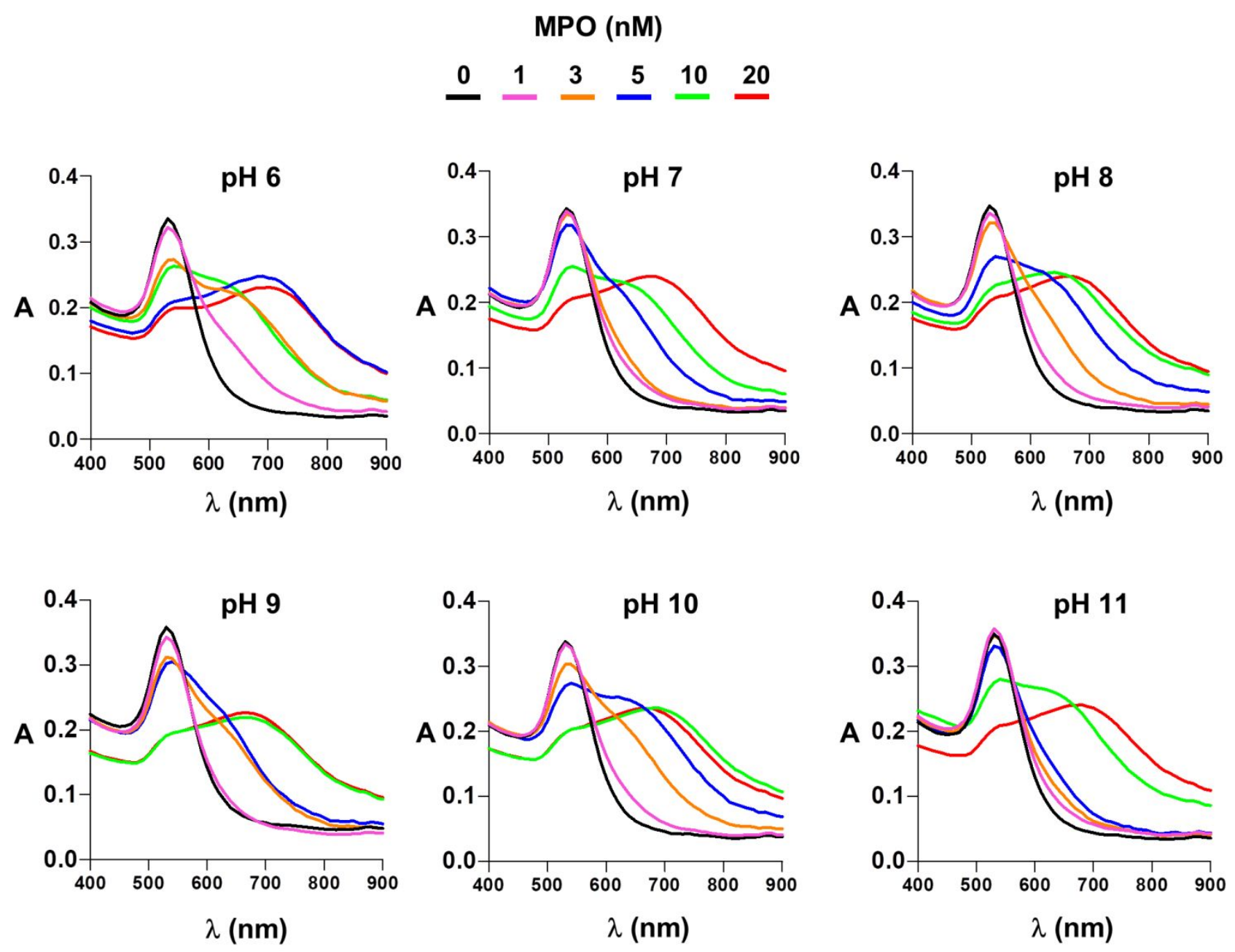

Figure S4. Spectra of AuNPs in the presence of MPO. Vis-NIR spectra of AuNPs at pH 6 to 11 in the presence of 0 (black), 1 (pink), 3 (orange), 5 (blue), 10 (green) or 20 (red) nM MPO. 


\section{S5. Evaluation of LOD for MPO with plasmonic nanosensors}

Figure S5 shows calibration plots for MPO at different $\mathrm{pH}$ values. The LOD for each plot was calculated by interpolating $\mathrm{S}_{\text {blank }}+3 \sigma_{\text {blank }}$ in the linear fit. Table S2 summarizes the LOD and linear range for each $\mathrm{pH}$ value.

pH 6

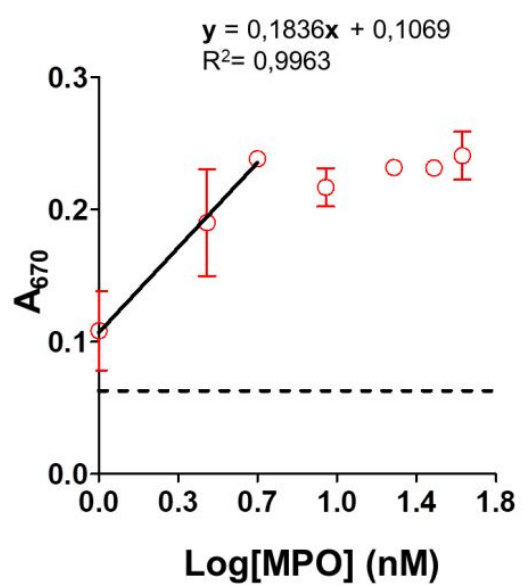

pH 9

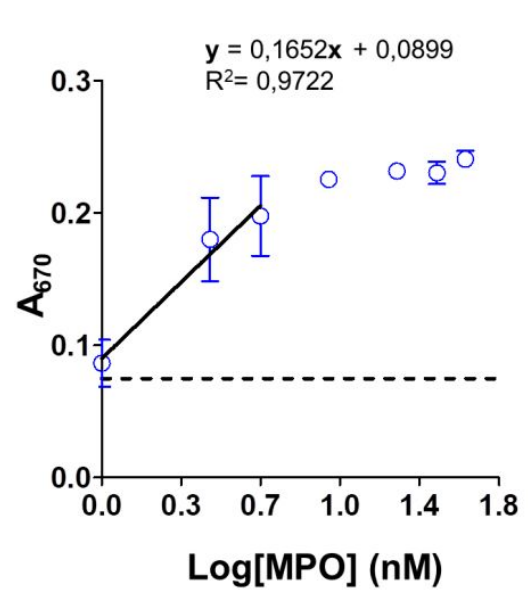

$\mathrm{pH} 7$

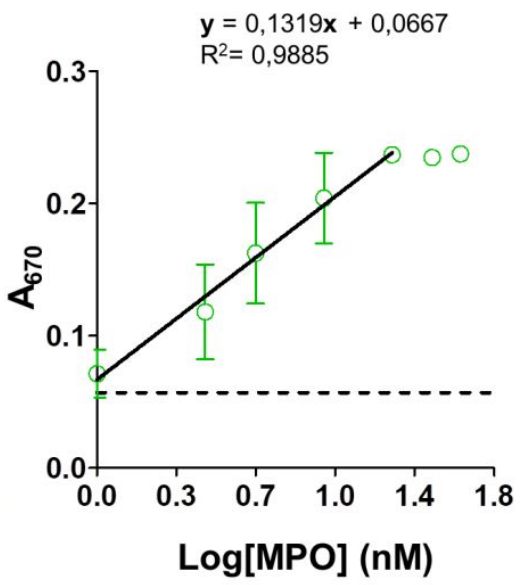

pH 10

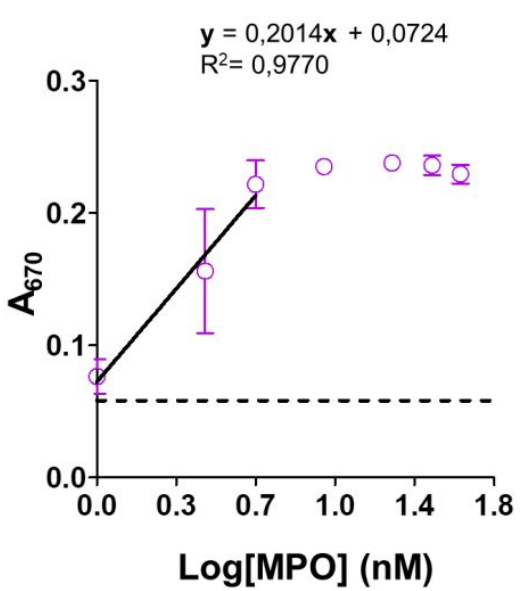

pH 8

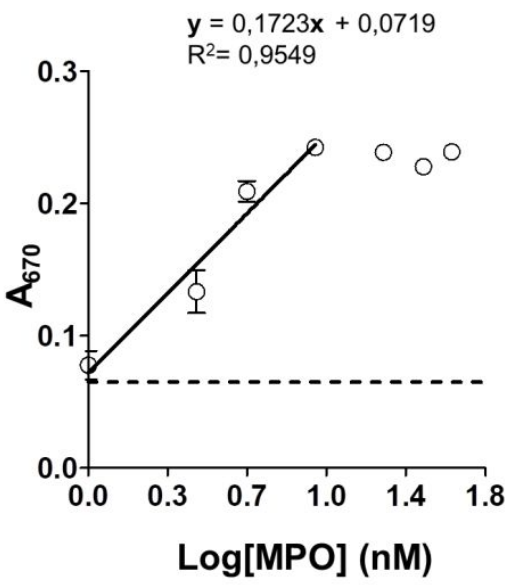

pH 11

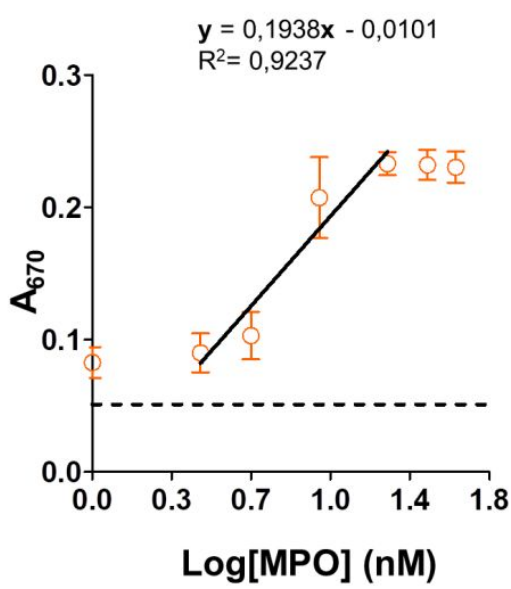

Figure S5. Detection of MPO at different pH values with plasmonic nanosensors. Absorbance at $670 \mathrm{~nm}$ of AuNPs after adding 1, 3, 5, 10, 20, 30 and $40 \mathrm{nM}$ MPO at pH 6 (red), 7 (green), 8 (black), 9 (blue), 10 (purple) and 11 (orange). Dots represent the mean value and error bars are the standard deviation $(n=3)$. Dotted lines represent three standard deviations above the mean value of the blank. 
Table S2. Limit of detection and linear range for MPO at different pH values

\begin{tabular}{ccc}
\hline $\mathbf{p H}$ & $\begin{array}{c}\text { LOD } \\
\text { (nM MPO) }\end{array}$ & $\begin{array}{c}\text { Linear range } \\
\text { (nM MPO) }\end{array}$ \\
\hline $\mathbf{6}$ & 0.59 & $1-5$ \\
$\mathbf{7}$ & 0.84 & $1-20$ \\
$\mathbf{8}$ & 0.98 & $1-10$ \\
$\mathbf{9}$ & 0.81 & $1-5$ \\
$\mathbf{1 0}$ & 0.85 & $1-5$ \\
$\mathbf{1 1}$ & 2.07 & $3-20$ \\
\hline
\end{tabular}




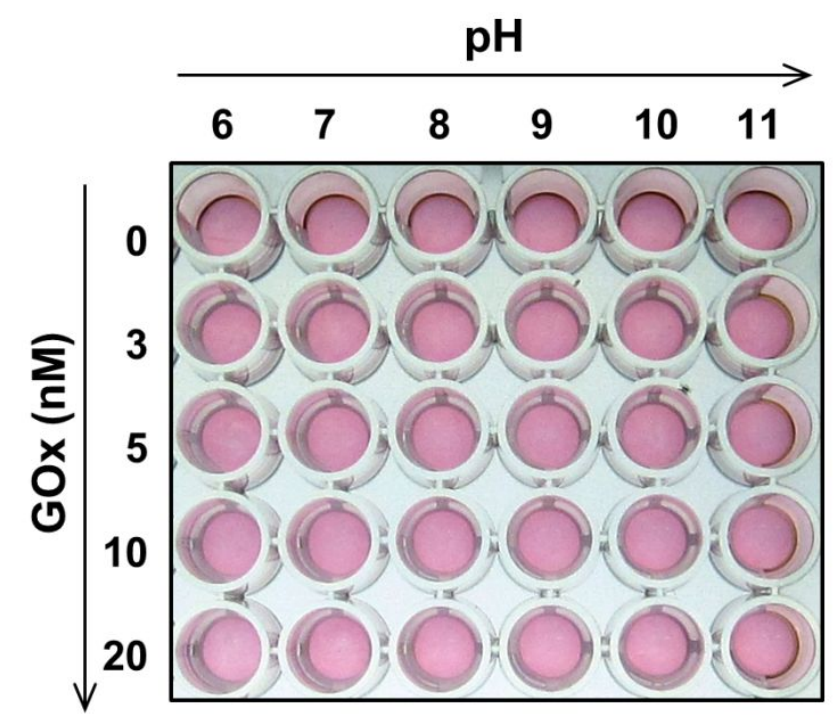

Figure S6. Aggregation pattern of AuNPs in the presence of GOx. Photograph of AuNPs colloids at $\mathrm{pH} 6$ to 11 in the presence of increasing concentrations of non-cationic glucose oxidase (GOx). 
pH 6
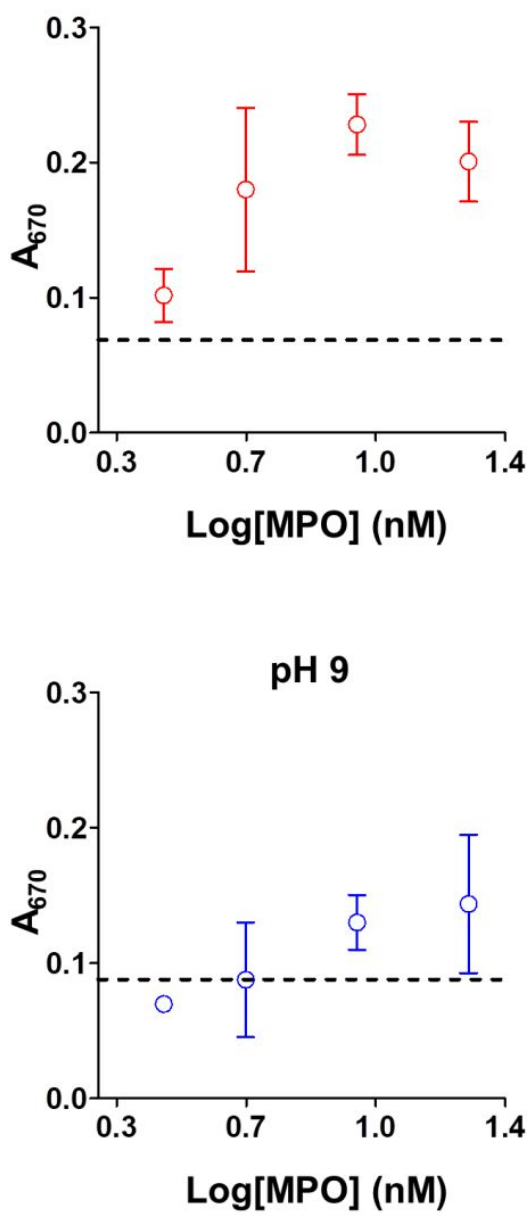

$\mathrm{pH} 7$
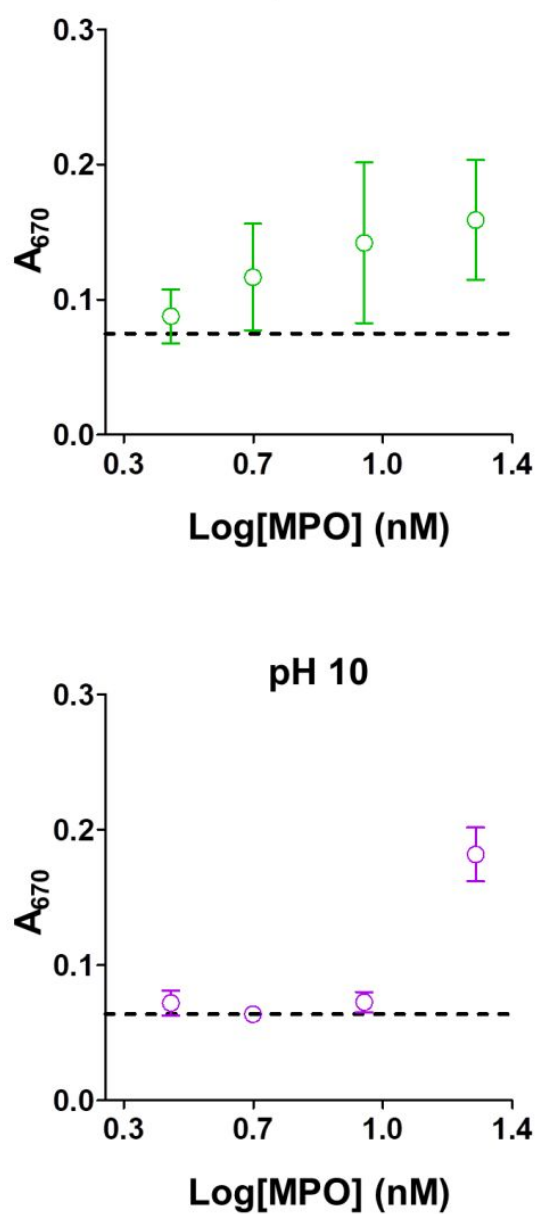

pH 8

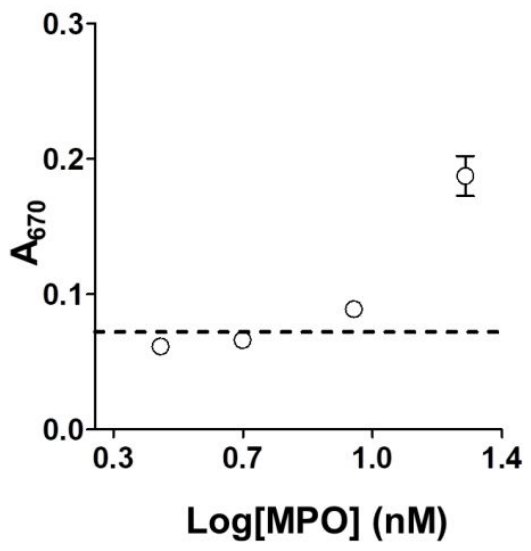

pH 11

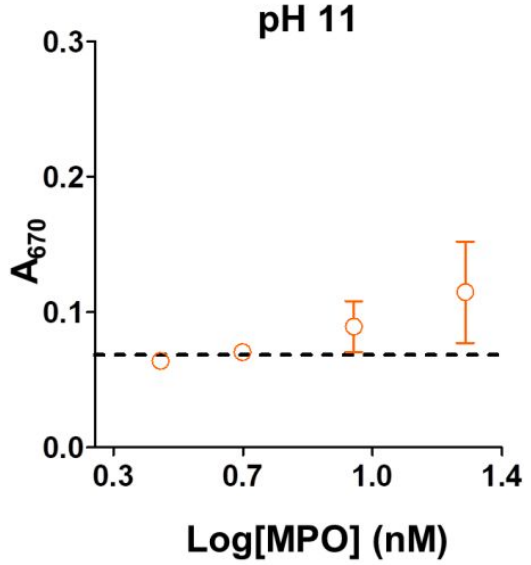

Figure S7. Detection of MPO at different $\mathrm{pH}$ values in the presence of GOx. Absorbance at $670 \mathrm{~nm}$ after adding 3, 5, 10 and $20 \mathrm{nM} \mathrm{MPO}$ at pH 6 (red), 7 (green), 8 (black), 9 (blue), 10 (purple) and 11 (orange) in the presence of $200 \mathrm{nM}$ GOx to AuNPs. Dots represent the mean value and error bars are the standard deviation $(n=3)$. Dotted lines represent three standard deviations above the mean value of the blank (with only GOx). 

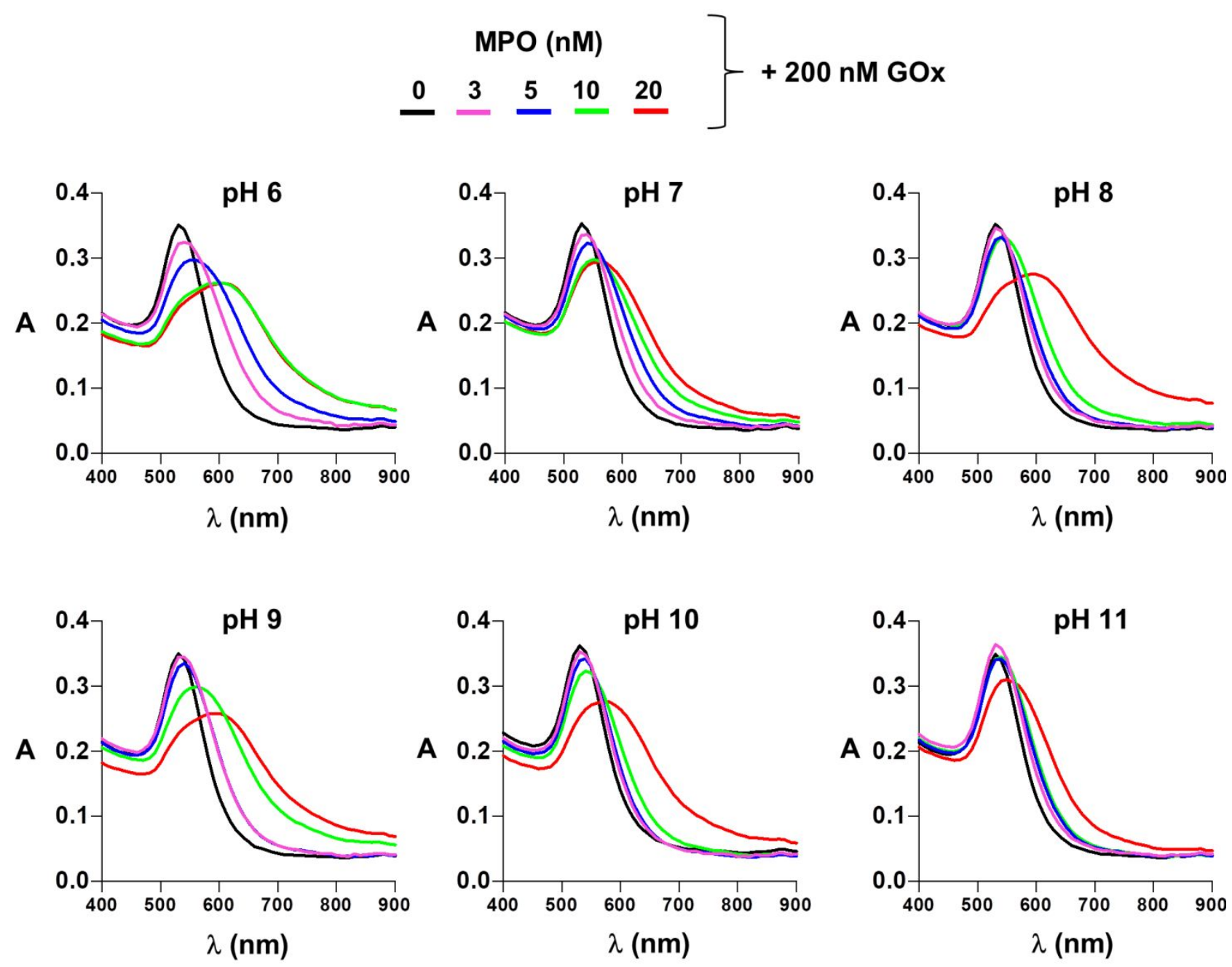

Figure S8. Spectra of AuNPs in the presence of MPO with GOx interference. Vis-NIR spectra of AuNPs colloids at pH 6 to 11 in the presence of $200 \mathrm{nM} \mathrm{GOx}$ with 0 (black), 1 (pink), 3 (orange), 5 (blue), 10 (green) or 20 (red) nM MPO. 


\section{S9. Isoelectric focusing}

We performed an isoelectric focusing electrophoresis with cell lysates obtained after degranulation protocol in order to demonstrate that granule-derived cationic proteins are released. Briefly, granulocytes from a healthy donor were isolated from peripheral blood as explained in the Materials and Methods section of the main text. Next, $2.5 \mathrm{~mL}$ of a cell suspension at $10^{3}$ cells $\cdot \mathrm{mL}^{-1}$ in RPMI was added to pre-blocked conical tubes with $2 \%$ PBSBSA and incubated $15 \mathrm{~min}$ at $37^{\circ} \mathrm{C}$ with $2.5 \mu \mathrm{M}$ ionomycin or DMSO. Then cells were centrifuged for $5 \mathrm{~min}$ at $1700 \mathrm{rpm}$ and the supernatants were removed. Cell lysates were obtained by repeating 3 times the following freeze-thaw-sonication cycle; first cell pellets were frozen in liquid nitrogen for $30 \mathrm{~s}$, then they were placed in a water bath at $37^{\circ} \mathrm{C}$ for 2 min and finally sonicated for 10 s. Finally cell lysates were diluted up to $500 \mu \mathrm{L}$ and concentrated x25 after centrifugation by using Amicon Ultra- 0.5 centrifugal $10 \mathrm{~K}$ filters (Millipore) following manufacturers' instructions. Isoelectric focusing was carried on a SAS3 automated compact electrophoresis analyser (Helena Biosciences). Briefly, $10 \mu \mathrm{L}$ of concentrated cell lysates was loaded into an agarose gel pH 3-10 (Helena Biosciences), then wicks along the anode $(+)$ and the cathode (-) were soaked with anode solution $(0.3 \mathrm{M}$ acetic acid) and cathode solution $(1 \mathrm{M} \mathrm{NaOH})$ respectively. After focusing at $400 \mathrm{~V}$ for $60 \mathrm{~min}$ agarose gel was rinsed in Milli-Q for 10 min and stained with Bio-Safe Coomassie G-250 Stain (BioRad) for $40 \mathrm{~min}$. Finally, agarose gel was rinsed in Milli-Q water for $10 \mathrm{~min}$ and the migration of proteins was imaged with the Odyssey infrared imaging system (LI-COR Biosciences) in the $700 \mathrm{~nm}$ channel.

In Fig. S9 cationic proteins are focused on the top of the $\mathrm{pH}$ gradient in cell lysates of nonstimulated granulocytes (black arrows in lanes 1 and 2). However, this zone is empty in lysates of pre-stimulated granulocytes with ionomycin (lane 3). These results demonstrate that granule-derived cationic proteins remain in cytoplasmic granules in resting cells and that they are released to SNs after following the degranulation protocol. 


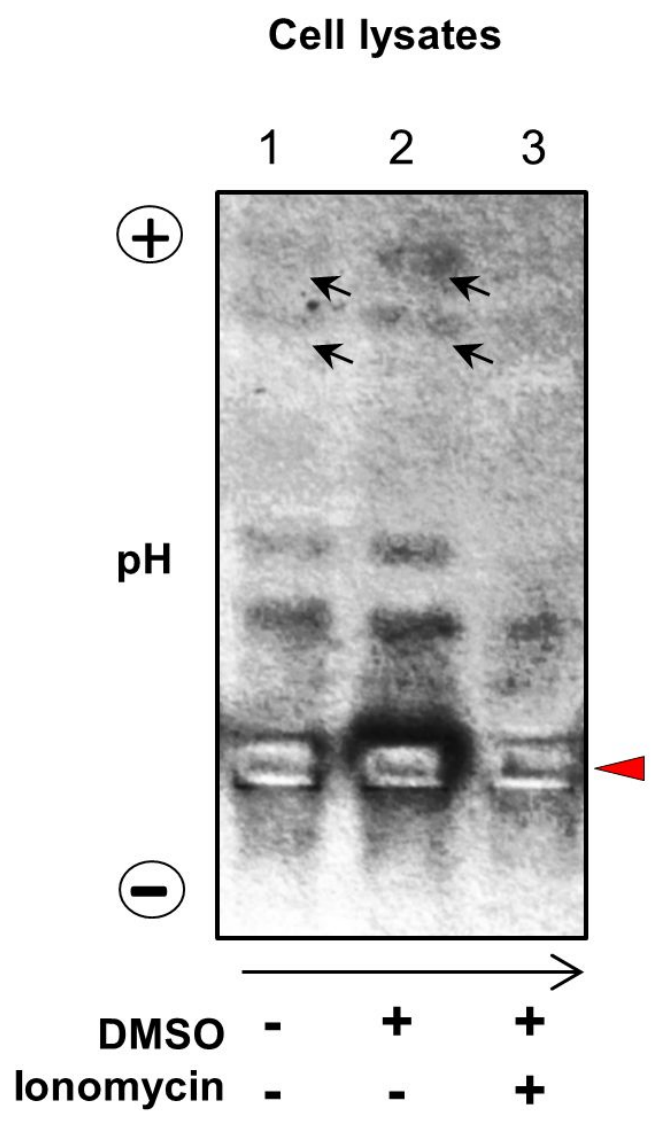

Figure S9. Isoelectric focusing of cell lysates after ionomycin stimulation. Migration of proteins after isoelectric focusing of cell lysates from cultures of granulocytes with only RPMI medium (lane 1), DMSO (lane 2) or DMSO and ionomycin (lane 3). Black arrows point to cationic proteins focused at higher $\mathrm{pH}$. The red arrow shows the sample loading point. Anode and cathode positions are indicated as (+) and (-) respectively. 


\section{S10. TMB assay with AuNPs}

We studied whether MPO from SNs enriched with granule-derived proteins adsorbs to the AuNPs depending on the $\mathrm{pH}$ of the solution with the following experiments. We obtained the SNs from 3 independent cultures following the degranulation protocol explained in the Materials and Methods section. Next $10 \mu \mathrm{L}$ of culture SNs was added to $1.5 \mathrm{~mL}$ Eppendorf conical tubes (previously blocked with 2\% PBS-BSA) and diluted 1:10 in $10 \mathrm{mM} \mathrm{PB}$ at pH 6 or 10. Then $100 \mu \mathrm{L}$ of AuNPs was added and incubated for $10 \mathrm{~min}$ at RT. The AuNPs were centrifuged at $7000 \mathrm{rpm}$ for $4 \mathrm{~min}$ and washed twice with $500 \mu \mathrm{L}$ of $\mathrm{PB}$ at pH 6 or 10 in each case. Next, the AuNPs were resuspended with $100 \mu \mathrm{L}$ of 1-step Ultra TMB (Thermo Scientific), incubated for $20 \mathrm{~min}$ at RT and subsequently centrifuged at $7000 \mathrm{rpm}$ for $4 \mathrm{~min}$. Finally, $80 \mu \mathrm{L}$ of the obtained SNs was added to wells of 96-well plates (Thermo Scientific) and the chromogenic reaction was stopped by adding $80 \mu \mathrm{L}$ of $2 \mathrm{~N} \mathrm{H}_{2} \mathrm{SO}_{4}$. Then, absorbance was measured at $450 \mathrm{~nm}$ in a PowerWave HT plate reader (Biotek).

Dotted bars in Fig. S10 show higher peroxidase activity around AuNPs pre-incubated with SNs obtained from cultures of granulocytes stimulated with ionomycin (enriched with granule-derived proteins) than those without stimulation (DMSO). Moreover the signal of peroxidase activity increases when the interaction between granule-derived proteins and AuNPs occurs at $\mathrm{pH}$ 6. These results demonstrate that the granule-derived MPO adsorbs to AuNPs in a pH-dependent manner. Therefore, the assembly of colloids in the plasmonic nanosensor is induced by the surface positive charge of granule-derived cationic proteins under low pH conditions as shown in Fig. 2. 


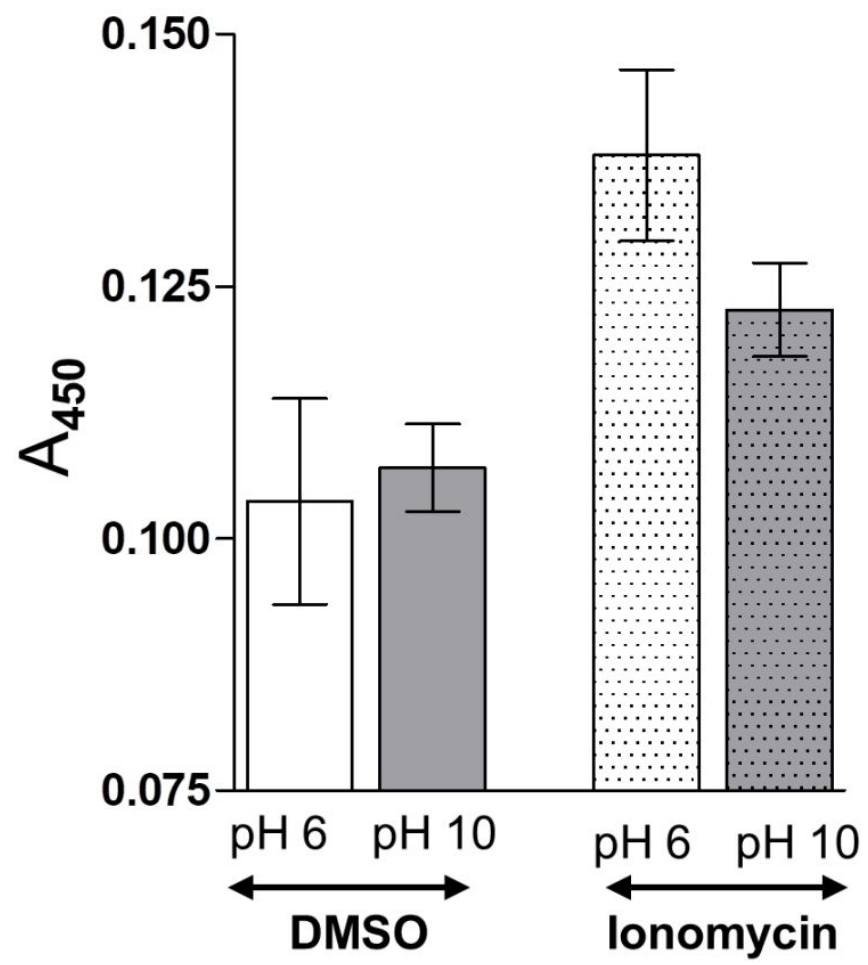

Figure S10. pH-dependent interaction of granule-derived MPO with AuNPs. Peroxidase activity in the surface of AuNPs after incubation with SNs obtained from cultures of granulocytes stimulated with ionomycin (dotted bars) or with DMSO (plain bars) at $\mathrm{pH} 6$ (white) or pH 10 (grey). Error bars are the standard deviation of 3 independent cultures. 


\section{S11. AuNPs clustering induced by RPMI medium}

We evaluate the potential interference of RPMI medium (balanced salt solution) in the aggregation of AuNPs. First, RPMI was diluted from 1:2 to 1:16 in Milli-Q water to a final volume of $500 \mu \mathrm{L}$ in polystyrene cuvettes for spectrophotometric analysis. Then $500 \mu \mathrm{L}$ of AuNPs was added and vis-NIR spectra were immediately collected. To detect granule proteins, RPMI medium was diluted from 1:10 to 1:1000 with $10 \mathrm{mM}$ phosphate buffer (PB) pH 6 prior to the addition of nanoparticles. Therefore, we also studied the potential interference of salts in RPMI diluted with PB. To this end, RPMI was diluted 1:10, 1:30, 1:100, 1:300 and 1:1000 in PB and $100 \mu \mathrm{L}$ of each solution was added to 96-well plate. Then, $100 \mu \mathrm{L}$ of AuNPs was added and vis-NIR spectra were immediately collected.

The composition of the RPMI medium is as follows: $0.4 \mathrm{mM} \mathrm{Ca}\left(\mathrm{NO}_{3}\right)_{2} \cdot 4 \mathrm{H}_{2} \mathrm{O}+0.4 \mathrm{mM}$ $\mathrm{MgSO}_{4}+5.4 \mathrm{mM} \mathrm{KCl}+23.8 \mathrm{mM} \mathrm{NaHCO}_{3}+102.3 \mathrm{mM} \mathrm{NaCl}+5.6 \mathrm{mM} \mathrm{Na} \mathrm{HPO}_{4}$. In Fig. S11A non-diluted RPMI induces the aggregation of AuNPs as expected from a solution containing a high salt content. When the concentration of salts decreases nanoparticles are less aggregated. When RPMI is diluted 1:10 or more they do not aggregate at all. Results are also referred to the concentration of the predominant cationic species $\left(\mathrm{Na}^{+}\right)$in the caption for the sake of comparison. Fig. S11B shows that diluting RPMI with PB does not aggregate the nanoparticles either. These results demonstrate that nanoparticle aggregation is not triggered by the presence of salts alone in our experimental conditions. 

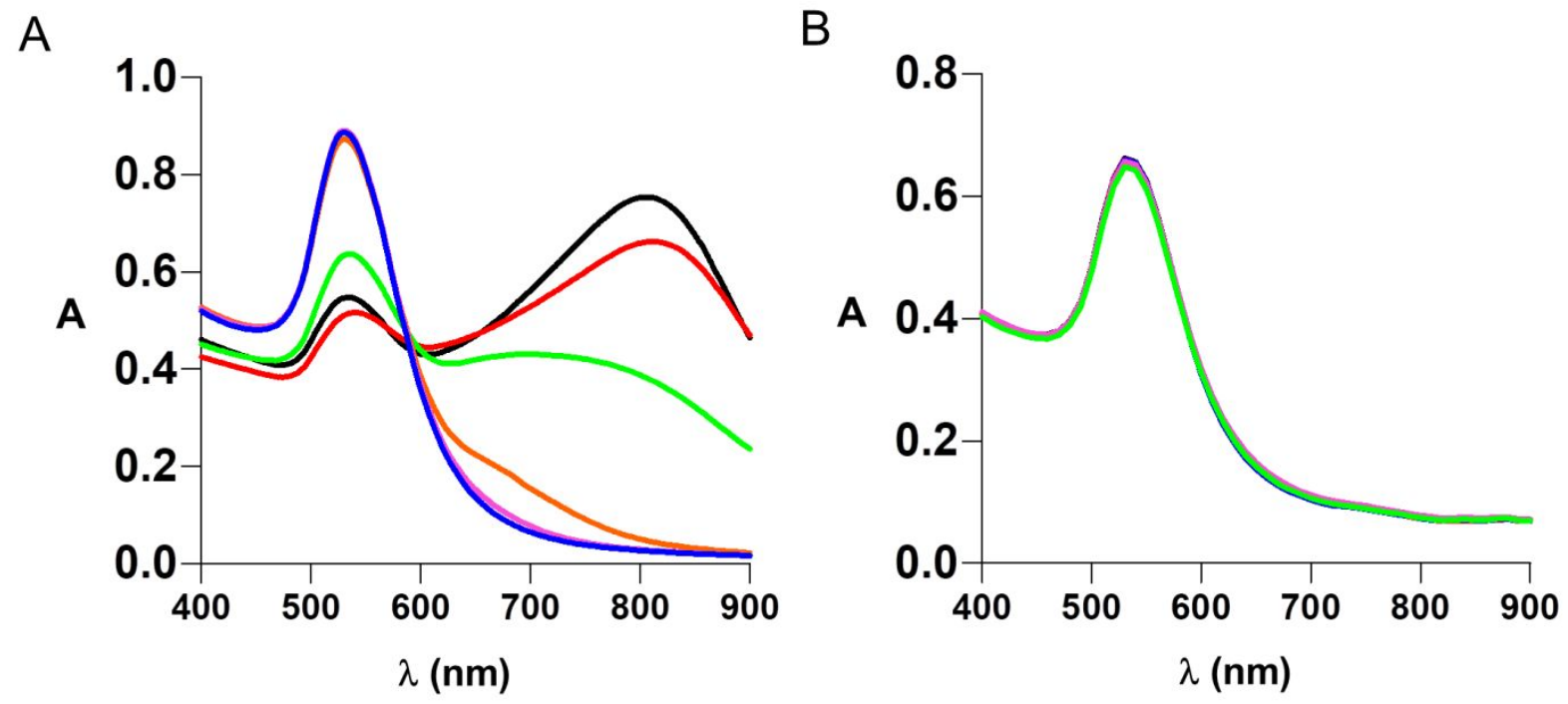

Figure S11. Spectra of AuNPs in the presence of RPMI. (A) Vis-NIR spectra of AuNPs after adding the same volume of non-diluted RPMI (black, $\left[\mathrm{Na}^{+}\right]=68.7 \mathrm{mM}$ ) or RPMI diluted 1:2 (red, $\left.\left[\mathrm{Na}^{+}\right]=34.3 \mathrm{mM}\right), 1: 4\left(\right.$ green, $\left.\left[\mathrm{Na}^{+}\right]=17.2 \mathrm{mM}\right), 1: 8$ (orange, $\left[\mathrm{Na}^{+}\right]=8.6$ $\mathrm{mM}$ ), 1:10 (pink, $\left[\mathrm{Na}^{+}\right]=6.9 \mathrm{mM}$ ) and 1:16 (blue, $\left[\mathrm{Na}^{+}\right]=8.6 \mathrm{mM}$ ) in water. (B) Vis-NIR spectra of AuNPs after adding RPMI diluted in PB (pH 6), 1:10 (pink, $\left[\mathrm{Na}^{+}\right]=16.9 \mathrm{mM}$ ), 1:30 (green, $\left.\left[\mathrm{Na}^{+}\right]=5.6 \mathrm{mM}\right), 1: 100\left(\right.$ black, $\left.\left[\mathrm{Na}^{+}\right]=1.7 \mathrm{mM}\right), 1: 300\left(\right.$ red, $\left.\left[\mathrm{Na}^{+}\right]=0.6 \mathrm{mM}\right)$ and 1:1000 (blue, $\left[\mathrm{Na}^{+}\right]=0.2 \mathrm{mM}$ ). 


\section{S12. AuNPs clustering induced by DMSO and ionomycin}

The supernatants of granulocytes cultures contain DMSO and ionomycin, which could interfere in the aggregation f AuNPs. In order to evaluate this, DMSO was diluted 1:10 (1.4 M) and 1:100 (140 mM) in Milli-Q water to a final volume of $500 \mu \mathrm{L}$. A stock solution of 4 $\mathrm{mM}$ ionomycin in DMSO was used to make 40,30, 20, 15, 10 and $5 \mu \mathrm{M}$ solutions in Milli-Q water to a final volume of $500 \mu \mathrm{L}$. Then all solutions were placed in polystyrene cuvettes for spectrophotometric analysis, $500 \mu \mathrm{L}$ of AuNPs was added and vis-NIR spectra were collected.

In the panel A of Fig. S12 DMSO at a concentration of $14 \mathrm{M}$ (non-diluted) and 1.4 M induces the aggregation of AuNPs. However, the DMSO-induced aggregation of AuNPs is prevented if the organic solvent is used at $140 \mathrm{mM}$. In the panel B of Fig. S12 ionomycin does not induce the aggregation of AuNPs. In our degranulation protocol DMSO is diluted 1:200 in order to obtain the working solution of ionomycin (which is used at a final concentration of $2.5 \mu \mathrm{M}$ ), then $5 \mu \mathrm{L}$ is added to granulocytes cultures (the final concentration of DMSO is 0.7 $\mathrm{mM}$ ). Thus, the results in Fig. S12 demonstrate that neither DMSO nor ionomycin induce the aggregation of AuNPs when culture supernatants are tested with our nanosensors.
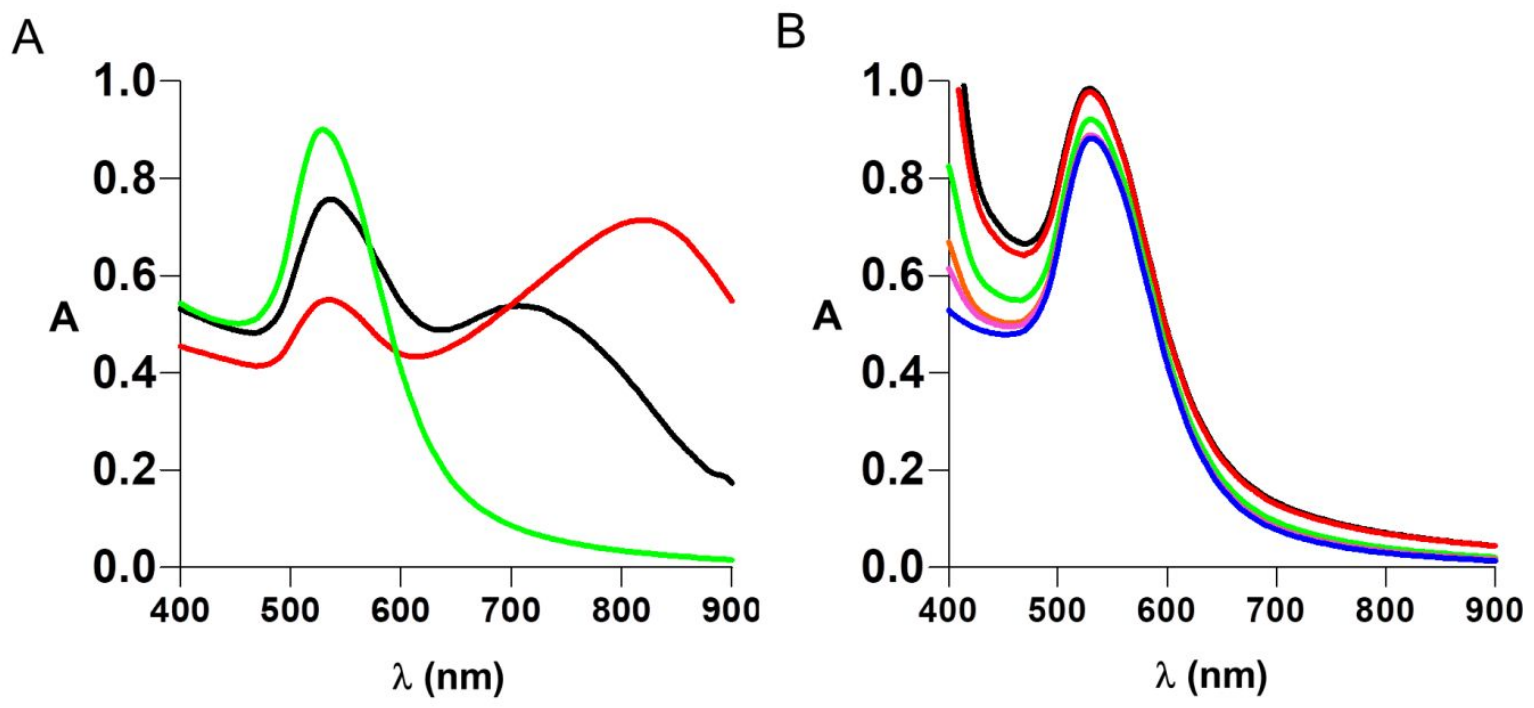

Figure S12. Spectra of AuNPs in the presence of DMSO and ionomycin. (A) Vis-NIR spectra of AuNPs colloids with non-diluted DMSO (black, $14 \mathrm{M}$ ) or DMSO diluted 1:10 (red, $1.4 \mathrm{M}$ ) and 1:100 (green, $140 \mathrm{mM}$ ). (B) Vis-NIR spectra of AuNPs colloids with ionomycin at $40 \mu \mathrm{M}$ (black), $30 \mu \mathrm{M}$ (red), $20 \mu \mathrm{M}$ (green), $15 \mu \mathrm{M}$ (orange), $10 \mu \mathrm{M}$ (pink) and $5 \mu \mathrm{M}$ (blue). 


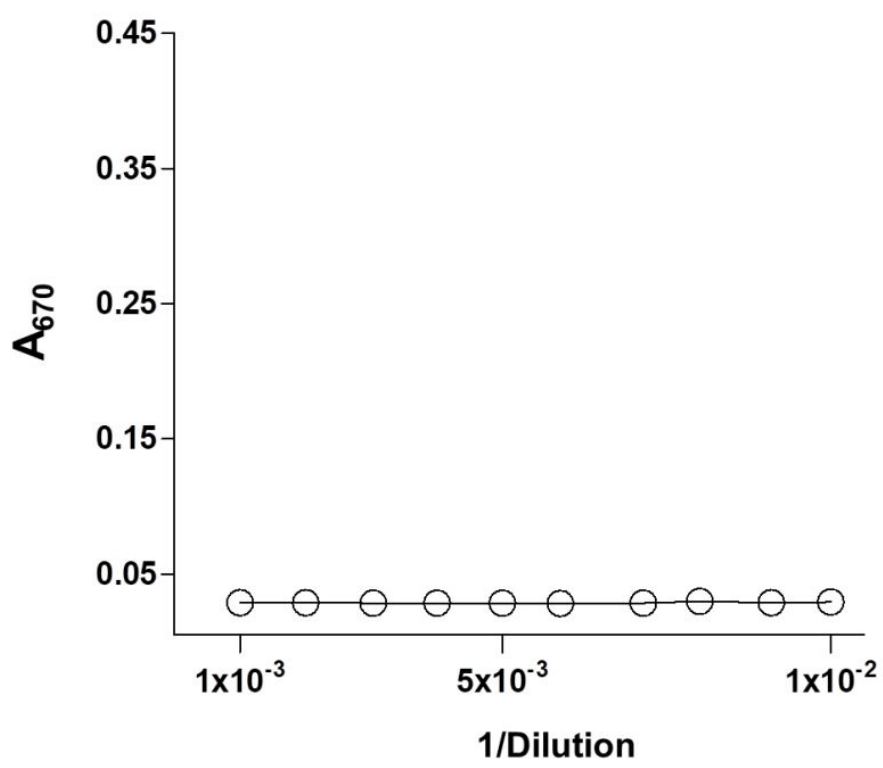

Figure S13. $\mathrm{A}_{670}$ of SNs in the absence of AuNPs. Absorbance at $670 \mathrm{~nm}$ of a SN from stimulated granulocytes from a healthy control diluted with $10 \mathrm{mM} \mathrm{PB} \mathrm{(pH} \mathrm{6).}$ 


\section{S14. Non-stimulated controls in the degranulation protocol}

We used SNs from granulocytes cultures with only DMSO (ionomycin solubilizer) as nonstimulated controls. As for ionomycin-stimulated cultures, SNs from controls with only DMSO were diluted from 1:100 to 1:1000 at $\mathrm{pH} 6$ and mixed with AuNPs (a more detailed procedure is shown in the Materials and Methods section).

In Fig. S14 the $\mathrm{A}_{670}$ values are lower than those detected with SNs of granulocyte cultures stimulated with ionomycin (Fig. 3B in the main text). Accordingly, blue-colored suspensions were obtained only at high $1 /$ dilution values, in contrast to ionomycin-stimulated cultures (inset in Fig. 3B in the main text). This indicates that SNs without ionomycin contain less concentrated proteins. Given that granulocytes are likely to degranulate spontaneously it is not surprising to observe basal signals in SNs from unstimulated cultures. This is in accordance with the detection of low levels of peroxidase activity in them (Fig. S2C). These results demonstrate that following our degranulation protocol SNs are enriched with granulederived cationic proteins.

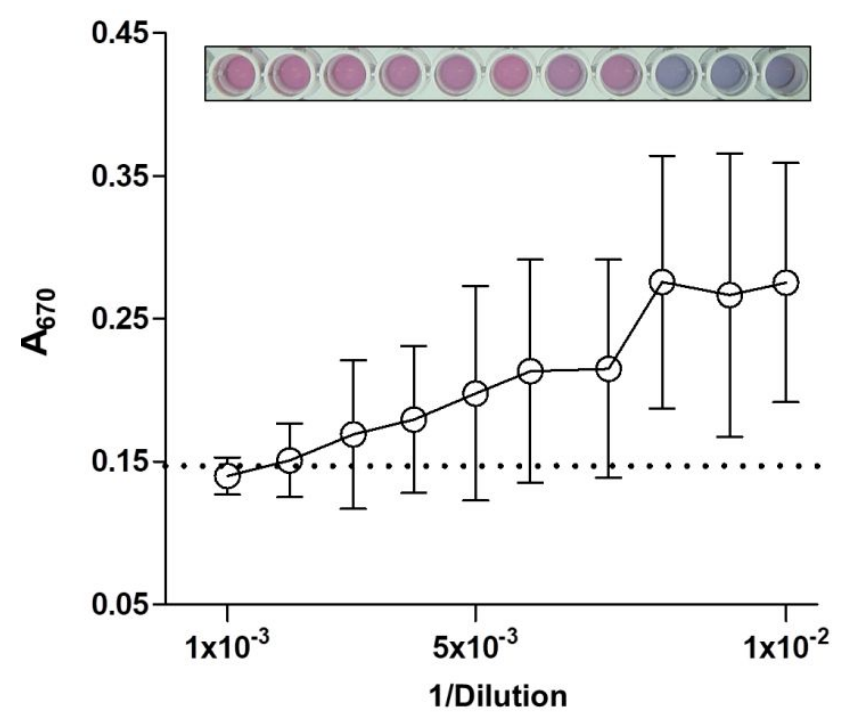

Figure S14. Aggregation of AuNPs with SNs from non-stimulated cultures. Absorbance at $670 \mathrm{~nm}$ after adding AuNPs to SNs of unstimulated granulocytes diluted from 1:1000 to 1:100 at pH6. Error bars are the standard deviation of 15 healthy controls. Dotted line represents two standard deviations above the mean of 50 blank tests. Inset show photographs of AuNPs. 


\section{S15. Protocol for control neutrophils pre-stimulation}

We purposed to demonstrate that the response of the plasmonic nanosensor for neutrophilic granulocytes hyperdegranulation depends on the cargo of granules within cells before the test performance. To this end we recreated the basal degranulated status of septic neutrophilic granulocytes in control cells from a healthy donor following our degranulation protocol with some modifications. After isolation of granulocytes and cell density adjustment (as explained in the Materials and Methods section) we added $500 \mu \mathrm{L}$ of cell suspension to Eppendorf conical tubes pre-blocked with 2\% PBS-BSA. Next we stimulated the cells with 2.5 $\mu \mathrm{M}$ ionomycin for $30 \mathrm{~min}$ at $\mathrm{RT}$ (controls with only $0.7 \mathrm{mM}$ DMSO were also included). After a gently centrifugation at $1200 \mathrm{rpm}$ for $5 \mathrm{~min}$, SNs were aspired and kept at $4{ }^{\circ} \mathrm{C}$ while we proceed to the second cell stimulation. Then cell pellets were resuspended with fresh RPMI pre-warmed medium and re-stimulated with $2.5 \mu \mathrm{M}$ ionomycin for $15 \mathrm{~min}$ at $37{ }^{\circ} \mathrm{C}$. Then additional SNs were obtained after centrifugation at $1700 \mathrm{rpm}$ for $5 \mathrm{~min}$. Finally we diluted all SNs from 1:20 to 1:100 in $10 \mathrm{mM} \mathrm{PB}$ at $\mathrm{pH} 6$ and we performed the plasmonic nanosensor test.

As expected, in Fig. S15 the $\mathrm{A}_{670}$ for granule proteins is consistently higher in all dilutions of SNs from cells stimulated with ionomycin than those without stimulation (DMSO). Interestingly, Fig. 4 in the main text shows that SNs of re-cultured cells yielded lower signals than cells treated with only DMSO during the first round of stimulation. Therefore, the nanoparticle aggregation is prevented when cells have partially released their granules in vitro. These results prompted us to evaluate the suitability of our plasmonic nanosensor for the detection of hyperdegranulation in septic neutrophilic granulocytes (which have depleted granules in vivo). 


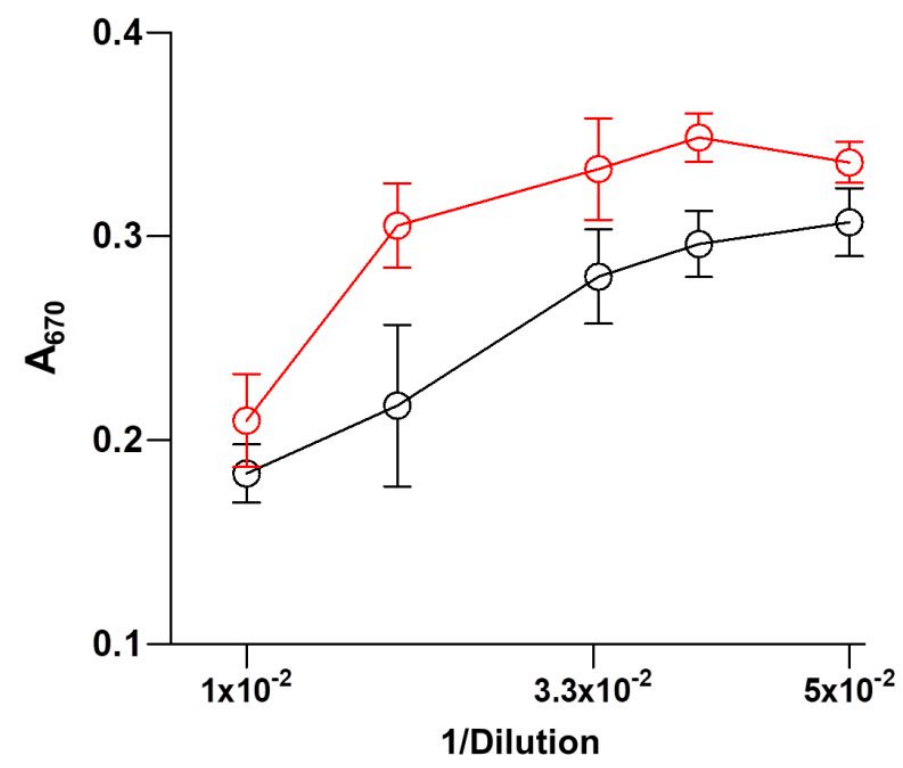

Figure S15. Plasmonic assay with granule-depleted cells. Absorbance at $670 \mathrm{~nm}$ after adding AuNPs to diluted SNs of granulocytes stimulated with ionomycin (Io, red lines) or DMSO (black lines) for $30 \mathrm{~min}$ at RT. Error bars are the standard deviation of 3 independent cultures. 


\section{S16. Densitometric analysis of color in photographs.}

We evaluated the pixel intensity from photographs in Fig. 5D of the main text by quantifying the "a" channel in the $\mathrm{L}^{*} \mathrm{a}$ *b color space with Adobe Photoshop. In Figure S16 the pixel intensity calculated from healthy controls (HC) is lower than the pixel intensity from sepsis patients (SP), which paves the way to using the densitometric analysis of photograph as an alternative to naked eye detection for colorimetric signal evaluation.

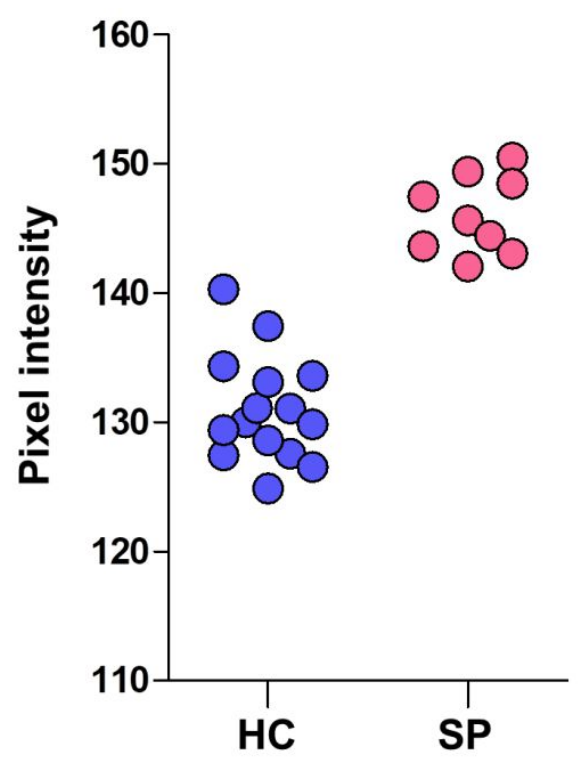

Figure S16. Color quantification from photographs. Pixel intensity of colorimetric signals yielded by the plasmonic nanosensor with SNs diluted 1:100 from stimulated granulocytes of healthy controls (HC, blue dots) and septic patients (SP, pink dots) at pH 6. 


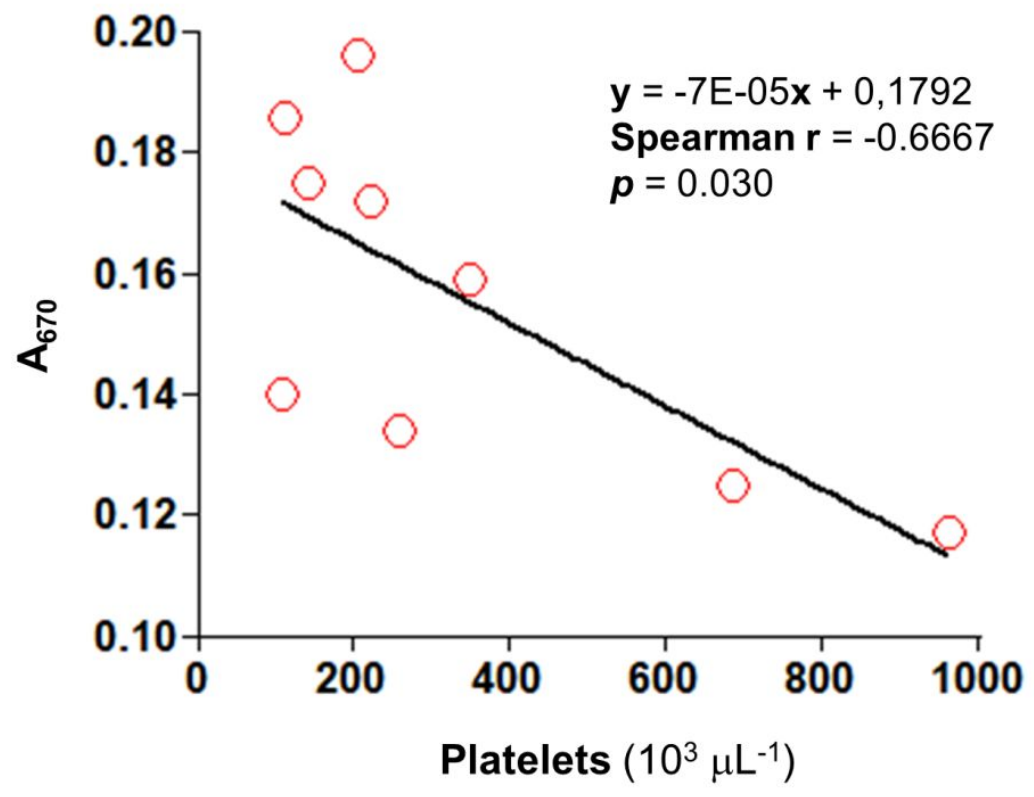

Figure S17. Correlation between plasmonic nanosensor signals and platelet counts. Absorbance at $670 \mathrm{~nm}$ after adding AuNPs to SNs (diluted 1:100 at $\mathrm{pH}$ 6) from ionomycinstimulated granulocytes of sepsis patients with respect to their absolute counts of circulating platelets at the time of sampling. 